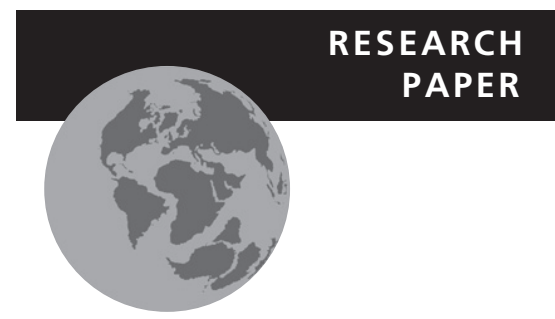

\title{
A predicted niche shift corresponds with increased thermal resistance in an invasive mite, Halotydeus destructor
}

\author{
Matthew P. Hill ${ }^{1 \star}$, Steven L. Chown ${ }^{2,3}$ and Ary A. Hoffmann ${ }^{1,4}$
}

${ }^{1}$ Department of Zoology, Bio21 Institute, The University of Melbourne, Parkville, Vic. 3010, Australia, ${ }^{2}$ Centre for Invasion Biology, Stellenbosch University, Stellenbosch, South Africa, ${ }^{3}$ School of Biological Sciences, Monash University, Melbourne, Vic. 3800, Australia, ${ }^{4}$ Department of Genetics, Bio21 Institute, The University of Melbourne, Parkville, Vic. 3010, Australia

\footnotetext{
${ }^{*}$ Correspondence: Matthew Peter Hill, Department of Zoology, University of Melbourne, Parkville, Vic. 3010, Australia. E-mail: hillmp@unimelb.edu.au
}

\begin{abstract}
Aim Predicted distributions of invasive species are often not congruent between their realized native and introduced ranges, but the reasons for this are rarely investigated empirically. We tested for niche shift in an invasive species using a simple framework combining environmental niche models (ENMs) and nichelimiting thermal tolerance traits.
\end{abstract}

Location Australia and South Africa.

Methods The red-legged earth mite, Halotydeus destructor, native to South Africa, is a major agricultural pest in Australia and has expanded its range to areas not predictable from its native range in the last 40 years. Revisiting recently constructed ENMs for $H$. destructor, we select populations in both native and invasive ranges that appear to occupy different niches. We characterize thermal tolerance traits and test for acclimation patterns of cold tolerance of these $H$. destructor populations to test for niche shifts.

Results Australian populations had an increased upper thermal threshold for movement and were able to recover from cold stress more rapidly than South African populations. Australian populations also differed in trait means from the likely source population in South Africa. Acclimation patterns were conserved across ranges for most populations, with $10^{\circ} \mathrm{C}$ acclimation lowering the onset of and recovery from cold tolerance and $15^{\circ} \mathrm{C}$ raising them when compared with field-acclimated populations.

Main conclusions These results support the prediction, based on ENMs, that $H$. destructor may have undergone a niche shift by adapting to environmental conditions in Australia. The increase in thermal resistance has implications for how this invasive species will respond to future climate change.

\section{Keywords}

Adaptation, Australia, environmental niche models, Halotydeus destructor, invasive species, niche shift, plasticity, South Africa, thermal tolerance.

\section{INTRODUCTION}

The potential distribution and spread of invasive species can be predicted by characterizing a species' niche through measuring traits, or more commonly through different types of species distribution models (Kearney \& Porter, 2009; Buckley et al., 2010; Jiménez-Valverde et al., 2011). One of the most common species distribution modelling methods for invasive species is the environmental niche model (ENM), which takes a known distribution of a species and correlates it with environmental

C 2013 Blackwell Publishing Ltd variables, characterizing an approximate realized niche of a species (Elith \& Leathwick, 2009; Jiménez-Valverde et al., 2011).

These approaches suggest that niche conservatism is evident for many invasive species. In a recent survey of invasive plant species only $15 \%$ had undergone niche shifts (Petitpierre et al., 2012). Nevertheless, predictions of invasive from native ranges, and the converse, based on ENMs or similar approaches may also prove inaccurate (Broennimann et al., 2007; Medley, 2010; Hill et al., 2012). When using ENMs to match distributions, it is assumed that the niche is conserved in space and time (Kolbe 
et al., 2010; Medley, 2010), and also that the species is in equilibrium with the environment in which it occurs (Guisan \& Thuiller, 2005; Gallien et al., 2012). These assumptions may be violated for invasive species, especially when species have not reached their final distributional extent in invaded areas. However, when the distribution of an invasive species is well sampled in both its native and invasive ranges, reciprocally projecting ENMs between ranges may give an indication of niche shifts (Broennimann et al., 2007; Medley, 2010; Hill et al., 2012), or at least generate hypotheses about the factors involved in potential niche shifts.

Niche shifts may be driven by a number of factors, including release from competitors, dispersal ability, climatic shift and adaptive shifts including increased plasticity within invasive populations (Sexton et al., 2009). Adaptation, or 'niche evolution', may involve a variety of traits within a given species, and enable a species to adapt to local conditions (Strayer et al., 2006). One of the clearest examples of rapid adaptation in the invasive range is that of the cane toad (Bufo marinus) in Australia. The species has displayed extensive niche shift through morphological adaptation, locomotor speed and invasion velocity, facilitating a massive range expansion across northern Australia (Phillips et al., 2006; Seebacher \& Franklin, 2011). Rapid evolution in niche-limiting photoperiodism traits has also been shown for the invasive mosquito Aedes albopictus (Urbanski et al., 2012). Niche shifts through evolution can thus allow improved performance of invasive species in new environments (Ebeling et al., 2008), though often this may be due largely to phenotypic plasticity (e.g. Ebeling et al., 2011) rather than the rapid evolution seen in toads and mosquitoes.

There is increasing evidence that thermal tolerance limits are linked to the distribution ranges of species (Hoffmann et al., 2005; Terblanche et al., 2006; Mitchell \& Hoffmann, 2010; Alford et al., 2012). By determining thermal limits for activity of populations or species, it is possible to gain some understanding of their likely distributions (Terblanche et al., 2007) and their potential to invade new geographic regions and deal with climate change (Overgaard et al., 2011). Despite this, thermal tolerance traits have rarely been considered across both native and invasive ranges to examine niche conservatism. Terrestrial arthropod species often exhibit differences in thermal tolerance limits across environmental gradients, including elevation and latitude (Gaston \& Chown, 1999; Hoffmann et al., 2005), with plastic and inherent variation across latitude more evident for lower than upper thermal limits (Hoffmann et al., 2005, 2012; Terblanche et al., 2006; Alford et al., 2012). It should be possible to explore the adaptive significance of this variation in invasive species by linking thermal traits to ENM predictions.

The invasive red-legged earth mite, Halotydeus destructor Tucker (Acari: Penthaleidae), is native to South Africa and an important agricultural pest in Australia (Ridsdill-Smith, 1997). Australian $H$. destructor populations are likely to originate from a population(s) near Cape Town (Qin, 1997) followed by a rapid spread across the southern grain-belt of Australia. Halotydeus destructor emerges during the cooler moist months around April-May and undergoes three generations before entering summer diapause around October-November (Ridsdill-Smith, 1997; Ridsdill-Smith et al., 2005). In the last 40 years H. destructor has undergone range expansion, moving inland to hotter and drier areas in eastern Australia. Due to its pest status, $H$. destructor has been extensively sampled and researched, mainly focusing on pesticide efficacy and resistance (Umina et al., 2012), competitive interactions (Umina \& Hoffmann, 2005) and potential biological control (Halliday, 2005).

Environmental niche models were recently applied to $H$. destructor distributions in both its native and invasive ranges, and suggested a niche shift in this species (Hill et al., 2012). Halotydeus destructor exists in environments in Australia different from those in the native range in South Africa, and vice versa. Furthermore, the ENMs also identified that aridity now limits the inland distribution of $H$. destructor, as opposed to a historic limit associated with winter rain, which may reflect an adaptive shift facilitating range expansion (Hill et al., 2012). Thus, changes in traits associated with aridity (particularly thermal and desiccation tolerance) may correlate with shifts in distributional limits. However, the range expansion could be due to other factors, including shifts in climate, changes in agricultural practices such as increased irrigation, or through changes to competitive, predatory or other biotic interactions in an area.

Halotydeus destructor therefore provides a unique opportunity to determine if apparent niche shifts in an invasive species can be linked to changes in thermal tolerance traits. We first revisit ENMs constructed by Hill et al. (2012) to select populations in both South Africa and Australia that appear to occupy different niches. Guided by these ENMs we test thermal tolerance traits in both native and invasive ranges, predicting differences in either basal thermal tolerance traits or plasticity that may have facilitated niche shifts. We also predict that South African populations display more variation in these thermal tolerance traits than do Australian populations, based on the relatively higher genetic diversity in South African populations (Qin, 1997). Further, we predict that Australian populations will be most similar in thermal tolerance to the putative source population near Cape Town (Qin, 1997). The ENMs and thermal tolerance traits together therefore provide a framework to understand niche shifts in this invasive species.

\section{MATERIAL AND METHODS}

\section{Sampling and ENM construction}

Halotydeus destructor has a wide range of host plant species that are common to both native and invasive ranges. We sampled roadside vegetation through agriculturally developed regions in both South Africa and Australia, targeting broad-leaved plants including clover (Trifolium spp.), Paterson's curse (Echium plantagineum), Plantago spp., capeweed (Arctotheca calendula), bristly ox-tongue (Picris echioides) and Oxalis species. Samples were taken using a Stihl SH55 blower vacuum (Andreas Stihl AG \& Co. KG, Waiblingen, Germany), with a metal sieve and specimens placed directly into ethanol. 
Methods for constructing ENMs for $H$. destructor are described in Hill et al. (2012). We added these new locality data, using GPS data recorded at each site, to revise the models (Appendix S1). To determine if there were any significant changes from the models developed by Hill et al. (2012), we performed niche equivalency tests with Schoener's $D$ in ENMtools (version 1.3; Warren et al., 2010) between all replicates of the original models and all replicates of the reconstructed models.

\section{Site selection}

Using the ENMs, we selected sites in both South Africa and Australia that may reflect different niches that $H$. destructor occupies within both geographic regions. To examine these regions in terms of temperature differences, we sampled across ENM output and extracted monthly minimum and maximum values (Appendix S2). We determined the northern inland limit of Halotydeus destructor by regularly sampling along roadsides, about $45 \mathrm{~km}$ north of Hay, New South Wales. We sampled four additional sites in New South Wales and Victoria and selected a further population at Conara, Tasmania. In South Africa we selected six populations from the southern end of the Western Cape province at Bredasdorp into the Northern Cape province at Steinkopf, based on population localities reported by Qin (1997). All samples were collected and experiments performed between June and October 2011. Experimental samples were collected using the same technique as for point locality data, except that mites were kept alive in containers with moist paper towel and fresh Trifolium spp. leaves. This is a standard method of collection for earth mites for ecological studies or pesticide efficacy (e.g. Umina \& Hoffmann, 2005; Umina et al., 2012). For each population, individuals were acclimated at either 10 or $15^{\circ} \mathrm{C}(14-\mathrm{h}$ dark, 10-h light cycle) for 2 weeks, with fresh Trifolium spp. leaves supplied every few days (see below). These two temperatures reflect the lower limit to development $\left(10^{\circ} \mathrm{C}\right)$ and are close to the optimum development $\left(18^{\circ} \mathrm{C}\right.$ - but mites held at this temperature constantly for 2 weeks show mortality, so it was lowered to $15^{\circ} \mathrm{C}$ ) from mass-rearing methods (see Ridsdill-Smith, 1997).

\section{Experiments}

All experiments were conducted using a thermoregulator controller (Australia: Grant GP-250/South Africa: Grant PZ1) linked to a waterbath (Australia: Grant R2/South Africa: Grant LTC) (Grant Instruments, Cambridge, Ltd, UK). We used a 50:50 mix of propylene glycol : water solution in these baths and the temperature-controlled fluid was pumped through channels in aluminium blocks (see below), allowing for accurate changes to temperature. Thermal tolerance traits were measured through ramping assays employing a dynamically changing temperature, which are likely to be more ecologically relevant than static assays (Mitchell \& Hoffmann, 2010; Overgaard et al., 2011). As variation in size may impact on thermal tolerance traits, we selected young adult mites of similar size for each experiment. We did not attempt to determine the sex of the mites, though we avoided the larger adult mites which are reproductive females (Ridsdill-Smith, 1997). In South Africa H. destructor occurs sympatrically with Halotydeus anthropus Qin \& Halliday, and is not readily distinguishable in the field. All South African field samples were identified to species post-hoc by examining coxal setae under $100 \times$ magnification (Qin \& Halliday, 1996).

\section{Heat tolerance}

To assess how high temperatures affect the voluntary activity levels of $H$. destructor, we constructed an aluminium block with an arena (7.5 $\mathrm{mm}$ deep, $25 \mathrm{~mm}$ diameter) connected to the waterbath (Hazell et al., 2008). The entire top surface of the block was covered with a Perspex block $(50 \mathrm{~mm} \times$ $100 \mathrm{~mm} \times 10 \mathrm{~mm}$ ). A small fan was placed next to the arena to prevent condensation. We used Fluon (Blades Biological, Edenbridge, UK) on the walls of the arena to keep individuals on the arena floor. However, some individuals overcame this barrier and were excluded from analysis. Experiments were recorded using a Dino-Lite AM411 digital microscope (AnMo Electronics Corporation, Taiwan) and DinoXcope software (AnMo Electronics Corporation, version 1.3.4). Video was analysed frame-by-frame using the VLC media player (VideoLAN, version 1.1.10, available at: http://www.videolan.org/, accessed July 2011). The temperature of the block was recorded every $10 \mathrm{~s}$ with an embedded universal temperature probe (model EI-1034; Electronic Innovations Corp., Lakewood, CO, USA) connected to a LabJack data acquisition device (Model U3; LabJack Corp., Lakewood, CO, USA).

The heat movement threshold (HMT) (Alford et al., 2012) is defined as the temperature at which the organism is unable to maintain voluntary coordinated function such as walking (Hazell et al., 2008). Heat coma temperature (HCT) is defined as when all movement of the organism, such as appendage twitching, ceases (Hazell et al., 2008; Alford et al., 2012). Each run consisted of an initial period of $5 \mathrm{~min}$ at $18{ }^{\circ} \mathrm{C}$ (optimal rearing temperature; Ridsdill-Smith, 1997) and then a fast ramp-incline to $28{ }^{\circ} \mathrm{C}\left(0.5^{\circ} \mathrm{C} \mathrm{min}{ }^{-1}\right)$. A ramp-incline $\left(0.1^{\circ} \mathrm{C} \mathrm{min}{ }^{-1}\right)$ was then conducted from $28^{\circ} \mathrm{C}$ until complete heat coma (indistinguishable from mortality). We only considered individuals that could be scored for both traits (see Table 1 for sample sizes). The HMT and HCT experiments were carried out on the first day and the critical thermal minimum $\left(\mathrm{CT}_{\mathrm{MIN}}\right)$ onset/recovery experiments on the third and (if necessary) fourth days post-acclimation.

\section{Cold tolerance}

Thermal tolerance of cold temperature varies across environmental gradients for temperate arthropod species (e.g. Hoffmann et al., 2005; Terblanche et al., 2006) and limits distributions of species such as Drosophila spp. (Kellermann et al., 2012). We measured $\mathrm{CT}_{\text {MIN }}$ by constructing an aluminium block $(100 \mathrm{~mm} \times 100 \mathrm{~mm} \times 10 \mathrm{~mm})$ with 19 wells ( $5 \mathrm{~mm}$ diameter $)$. The wells were arranged in a circle and the middle well was used as a control, with a thermocouple (type K) secured in place. Due to the relatively quick ramping rate and the active nature of the 
Table 1 Populations of Halotydeus destructor used in this study. Numbers represent individuals used in each experiment and treatment, heat movement threshold (HMT), heat coma temperature (HCT) and critical thermal minimum (CT $\mathrm{MIN}_{\text {). }}$.

\begin{tabular}{|c|c|c|c|c|c|c|c|c|}
\hline & \multirow[t]{2}{*}{ Reference } & \multirow[t]{2}{*}{ Locality } & \multirow[t]{2}{*}{ Latitude } & \multirow[t]{2}{*}{ Longitude } & \multicolumn{4}{|c|}{ Experiment/treatment } \\
\hline & & & & & $\begin{array}{l}\text { HMT/ } \\
\text { HCT }\end{array}$ & $\begin{array}{l}\mathrm{CT}_{\mathrm{MIN}} \\
\text { field }\end{array}$ & $\begin{array}{l}\mathrm{CT}_{\mathrm{MIN}} \\
10^{\circ} \mathrm{C}\end{array}$ & $\begin{array}{l}\mathrm{CT}_{\mathrm{MIN}} \\
15^{\circ} \mathrm{C}\end{array}$ \\
\hline \multirow[t]{6}{*}{ Australia } & Hay & Hay & -33.9039 & 144.8844 & 39 & 36 & 31 & 35 \\
\hline & Wang & Wanganella & -35.2307 & 144.8198 & 52 & 37 & 35 & 20 \\
\hline & Hcte & Heathcote & -36.9448 & 144.7304 & 48 & 39 & 40 & 32 \\
\hline & Echu & Echuca & -36.2706 & 144.7037 & 46 & & & \\
\hline & Winc & Winchelsea & -38.2142 & 144.1177 & 44 & 34 & 37 & 22 \\
\hline & Cnra & Conara & -41.8299 & 147.4362 & 46 & & & \\
\hline \multirow[t]{6}{*}{ South Africa } & Skpf & Steinkopf & -29.3888 & 17.803 & 47 & 29 & 36 & 15 \\
\hline & Vanr & Vanrhynsdorp & -31.6428 & 18.7191 & 44 & & & \\
\hline & Ende & Eendekuil & -32.7128 & 18.9226 & 52 & & & \\
\hline & Stel & Stellenbosch & -33.9286 & 18.8699 & 43 & 38 & 38 & 23 \\
\hline & Cale & Caledon & -34.2088 & 19.3991 & 48 & & & \\
\hline & Bdrp & Bredasdorp & -34.4966 & 20.0882 & 38 & 43 & 32 & 23 \\
\hline
\end{tabular}

mites, replicates consisted of around 10 individuals for ease of scoring. A piece of Perspex $(100 \mathrm{~mm} \times 100 \mathrm{~mm} \times 3 \mathrm{~mm})$ was placed on top of the arenas. Mites were viewed under $40 \times$ magnification and scored directly.

We tested field-collected, $10^{\circ} \mathrm{C}$-acclimated and $15^{\circ} \mathrm{C}$ acclimated individuals from each population with the $\mathrm{CT}_{\mathrm{MIN}}$ ramping profile of Sinclair et al. (2006) which measures both an onset and recovery trait. The temperature was cooled from $18{ }^{\circ} \mathrm{C}$ down to $8^{\circ} \mathrm{C}\left(0.5^{\circ} \mathrm{C} \mathrm{min}^{-1}\right)$ and then taken down further to $-5^{\circ} \mathrm{C}\left(0.25^{\circ} \mathrm{C} \mathrm{min}^{-1}\right)$, to measure the onset of $\mathrm{CT}_{\mathrm{MIN}}$. We then held the temperature for $5 \mathrm{~min}$ before ramping up $\left(0.25^{\circ} \mathrm{C}\right.$ $\mathrm{min}^{-1}$ ) until complete reanimation of all individuals, recording this as the recovery trait from $\mathrm{CT}_{\mathrm{MIN}}$ (Sinclair et al., 2006). Only individuals that could be scored for both traits were considered for analysis. The number of individuals tested per population and country are shown in Table 1.

\section{Statistical analysis}

All statistical analyses were performed in sPss (version 20; 2011, IBM). To test for differences in HMT and HCT trait means between Australian and South African populations, we performed nested ANOVAs. Population was nested within country and included as a random effect. To test for differences in $\mathrm{CT}_{\mathrm{MIN}}$ onset and recovery traits, we performed nested ANOVAs as for HMT/HCT, but added acclimation treatment as a fixed effect to the models and as an interaction term. We initially included an interaction term between acclimation and population (nested) but this term was incorporated into the error term to increase the denominator degrees of freedom in F-tests, although the outcome of the analyses was the same regardless of the approach followed.

We tested if thermal tolerance trait means vary within Australia or within South Africa by constructing temperature covariates that may influence populations of $H$. destructor. The first consisted of the weather station data nearest to each sampling point (Australian Bureau of Meteorology, accessed February 2012; South African Weather Service, requested February 2012). We obtained 2 weeks of temperature data prior to each field collection, summarized the daily upper and lower values into temperature extremes and built an isothermality index (daily minimum and maximum values divided by means for time period). To test for population differences we collapsed aggregated replicates to a single population mean and ran general linear models for each country respectively, incorporating these covariates.

Stellenbosch is approximately $50 \mathrm{~km}$ from Cape Town and is likely to represent a population close to the one that first colonized Australia. We tested if Australian populations were significantly different from this source population by performing one-way ANOVAs between Stellenbosch and Australian populations for each trait.

\section{RESULTS}

\section{Distribution modelling}

We added 19 distribution points to the South African dataset and 91 to the Australian dataset, including 15 in Tasmania. This gave a total of 50 points for South Africa (originally 31) and 621 points for Australia (originally 530). The revised models, following the methods outlined in Hill et al. (2012), are presented in Fig. 1. We found no significant difference in niche overlap scores (Schoener's D) between all sets of replicates for the original and reconstructed models with the new distribution data. Consequently, the revised ENMs do not reveal any new information about the niches of $H$. destructor, but support the original ENMs of Hill et al. (2012). 


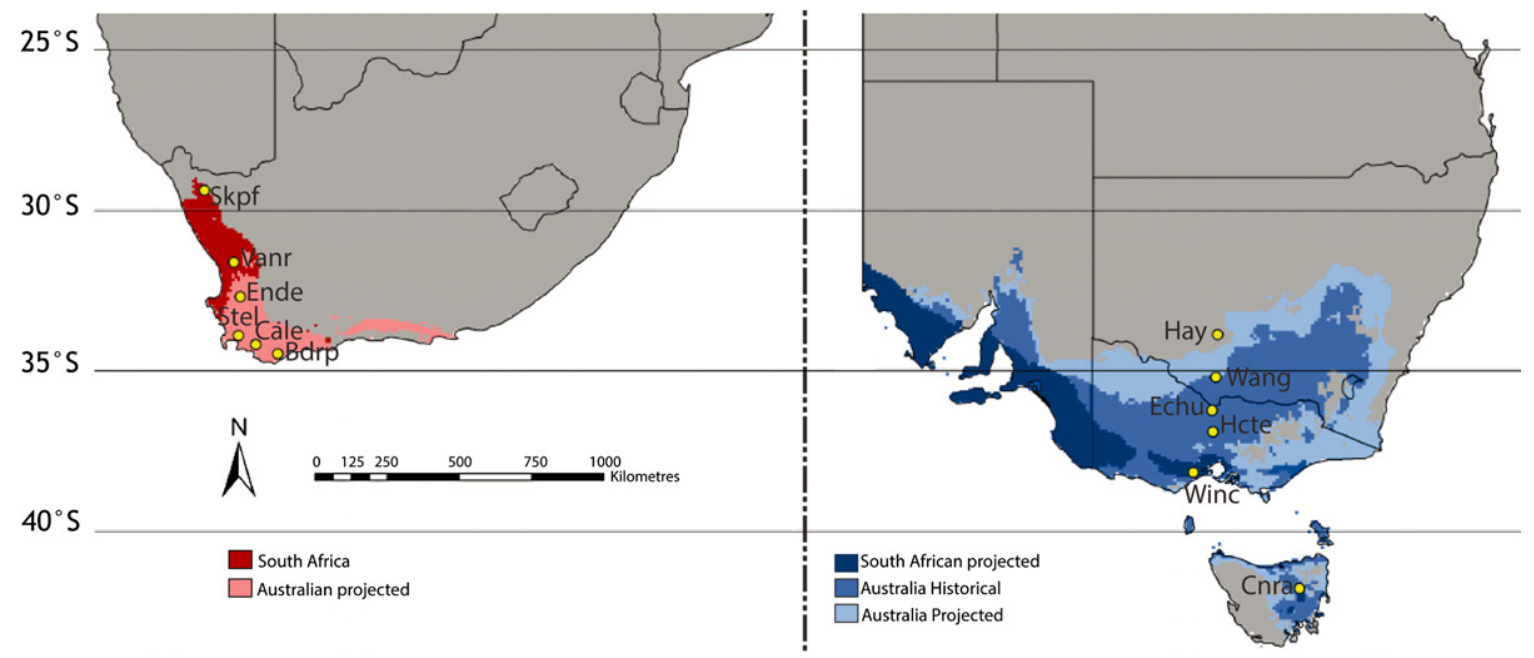

Figure 1 Population sampling of Halotydeus destructor in Australia (right) and South Africa (left) on top of the revised environmental niche models of Hill et al. (2012). Refer to Table 1 for population names. Shading in South Africa represents model prediction for South Africa (dark shading) and model projection from Australia (light shading). Shading in Australia represents South African model projection (dark shading), historical model prediction (intermediate shading) and present distribution prediction (light shading). All models were thresholded at least training presence $-5 \%$ error $($ LTE -5$)$ to display core climatic suitability for each dataset.

\section{Populations sampled}

Figure 1 shows the reconstructed ENMs of Hill et al. (2012) and locations of populations sampled from geographic areas suggesting different environments from model predictions. In particular, the region of range expansion in Australia is characterized by having lower minimum temperatures across winter months than both the native South African distribution and the historical distribution in Australia (Appendix S1). We used six populations in South Africa and six populations in Australia to assess HMT and HCT (Table 1). For $\mathrm{CT}_{\text {MIN }}$ we only tested four populations in Australia and three in South Africa due to time limitations.

\section{Heat tolerance}

For HMT and HCT, we tested 557 individuals of $H$. destructor across the 12 populations (Table 1). South African populations differed significantly for both heat tolerance traits, contributing to an overall population effect (Table 2, Fig. 2). There was no significant difference among populations of $H$. destructor in Australia for either HMT or for HCT (Table 2). Regression analysis indicated that isothermality of temperatures 2 weeks prior to collection was associated with Australian population means of HCT $(t=-3.184$, d.f. $=1, P=0.033)$, but not for South Africa $(t=1.138$, d.f. $=1, P=0.319)$.

For both heat tolerance traits, means were higher in the invasive populations (Fig. 2), and the effect of country was significant for HMT and marginally non-significant for HCT (Table 2). Heat movement threshold (Fig. 2) was lower for South Africa $\left(\right.$ mean $=31.84^{\circ} \mathrm{C}$ ) than Australia (mean $=$ $33.58^{\circ} \mathrm{C}$ ). Heat coma temperature (Fig. 2) was also lower in
South Africa $\left(\right.$ mean $\left.=34.96^{\circ} \mathrm{C}\right)$ compared with Australia $\left(\right.$ mean $\left.=35.83^{\circ} \mathrm{C}\right)$.

\section{Cold tolerance}

We tested $675 \mathrm{H}$. destructor (Table 1), and Fig. 3 shows the trait means for $\mathrm{CT}_{\mathrm{MIN}}$ onset and recovery. For the $\mathrm{CT}_{\mathrm{MIN}}$ experiments on field-collected populations, both $\mathrm{CT}_{\mathrm{MIN}}$ traits were significantly different among populations from South Africa, in contrast to the Australian populations where a significant difference was detected for onset but not recovery (Table 2). There was no interaction between country and acclimation treatment for either trait (Table 3), suggesting similar patterns regardless of acclimation. Onset was not significantly different between countries, but for the $\mathrm{CT}_{\mathrm{MIN}}$ recovery trait there was a significant country effect (Table 3 ) with Australian populations recovering from cold stress at a relatively lower temperature (means: South Africa $=7.84{ }^{\circ} \mathrm{C}$; Australia $=4.66^{\circ} \mathrm{C}$ ). The acclimation treatment had a significant effect on $\mathrm{CT}_{\text {MIN }}$ recovery (Table 3). Generally, $10^{\circ} \mathrm{C}$ acclimation decreased $\mathrm{CT}_{\text {MIN }}$ onset trait values when compared with $15^{\circ} \mathrm{C}$, and field acclimated mites tended to be intermediate (Fig. 3). However, for one of the Australian populations, Hay, a contrasting acclimation response from the rest of Australian populations was displayed for $\mathrm{CT}_{\mathrm{MIN}}$ onset, and no acclimation response for recovery. Within all Australian populations there was a significant interaction between acclimation and population for $\mathrm{CT}_{\mathrm{MIN}}$ recovery, but this interaction was not significant for South Africa (Table 4). Because only three populations from South Africa were scored for cold tolerance, no attempt was made to test for correlations between cold tolerance and environmental factors. 


\begin{tabular}{|c|c|c|c|c|c|c|}
\hline Trait/effect & d.f. & $\begin{array}{l}\text { Mean } \\
\text { square }\end{array}$ & $F$ & Error & $\begin{array}{l}\text { d.f. } \\
\text { (error) }\end{array}$ & Significance \\
\hline \multicolumn{7}{|l|}{ HMT } \\
\hline Country & 1 & 18.324 & 6.009 & 3.050 & 10 & 0.034 \\
\hline Population (country) & 10 & 3.050 & 9.129 & 0.334 & 12 & $<0.001$ \\
\hline Australian populations & 5 & 1.742 & 2.965 & 3.524 & 6 & 0.109 \\
\hline South African populations & 5 & 4.357 & 53.948 & 0.081 & 6 & $<0.001$ \\
\hline \multicolumn{7}{|l|}{ HCT } \\
\hline Country & 1 & 4.535 & 3.990 & 1.136 & 10 & 0.074 \\
\hline Population (country) & 10 & 1.136 & 10.378 & 0.110 & 12 & $<0.001$ \\
\hline Australian populations & 5 & 0.377 & 2.720 & 0.833 & 6 & 0.128 \\
\hline South African populations & 5 & 1.895 & 23.618 & 0.482 & 6 & 0.001 \\
\hline \multicolumn{7}{|l|}{$\mathrm{CT}_{\mathrm{MIN}}$ onset } \\
\hline Country & 1 & 0.089 & 0.095 & 0.936 & 5.028 & 0.770 \\
\hline Population (country) & 5 & 0.949 & 6.121 & 0.155 & 21 & 0.001 \\
\hline Australian populations & 3 & 0.787 & 5.299 & 0.149 & 12 & 0.015 \\
\hline South African populations & 2 & 1.191 & 7.281 & 0.164 & 9 & 0.013 \\
\hline \multicolumn{7}{|l|}{$\mathrm{CT}_{\mathrm{MIN}}$ recovery } \\
\hline Country & 1 & 67.608 & 10.481 & 6.451 & 5.042 & 0.023 \\
\hline Population (country) & 5 & 6.532 & 3.975 & 1.643 & 21 & 0.011 \\
\hline Australian populations & 3 & 1.756 & 0.926 & 1.896 & 12 & 0.458 \\
\hline South African populations & 2 & 13.695 & 10.488 & 1.306 & 9 & 0.004 \\
\hline
\end{tabular}

Table 2 ANOVAs for heat movement threshold (HMT), heat coma temperature (HCT), critical thermal minimum $\left(\mathrm{CT}_{\mathrm{MIN}}\right)$ onset and $\mathrm{CT}_{\mathrm{MIN}}$ recovery of field collected populations of Halotydeus destructor. Significant terms $(P<0.05)$ are indicated in bold.

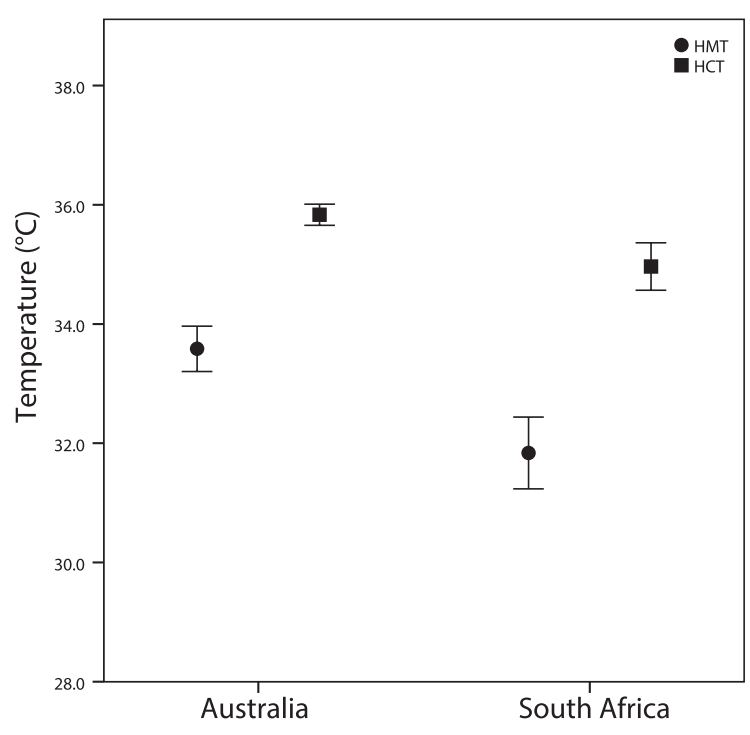

Figure 2 Heat movement threshold (HMT) (circles) and heat coma temperature (HCT) (squares) for Australia and South Africa. Points represent mean of each country. Error bars signify one standard error for means.

\section{Comparing Australian populations to source population}

The one-way ANOVAs comparing Stellenbosch with Australian populations revealed significant differences in HCT (means: Stellenbosch $=34.96^{\circ} \mathrm{C} ; \quad$ Australia $\left.=35.83^{\circ} \mathrm{C}\right) \quad\left(F_{6,7}=4.469\right.$, $P=0.035)$ and $\mathrm{CT}_{\mathrm{MIN}}$ recovery (means: Stellenbosch $=7.17^{\circ} \mathrm{C}$; Australia $\left.=4.43^{\circ} \mathrm{C}\right)\left(F_{5,60}=6.901, P<0.001\right)$, a marginally nonsignificant difference for HMT (means: Stellenbosch $=32.47^{\circ} \mathrm{C}$;
Australia $\left.=33.58^{\circ} \mathrm{C}\right)\left(F_{6,7}=3.552, P=0.061\right)$ and no significant difference for $\mathrm{CT}_{\mathrm{MIN}}$ onset. Note that for $\mathrm{CT}_{\mathrm{MIN}}$ recovery data were pooled across Australian populations that did not differ significantly, whereas the other comparisons were based on population means.

\section{DISCUSSION}

We predicted that Australian populations of $H$. destructor would differ in basal thermal tolerance traits and/or plasticity from South African ones, and that such differences may have contributed to a climatic niche shift. Australian populations of $H$. destructor had a higher trait mean for HMT, a lower trait mean (quicker recovery) for $\mathrm{CT}_{\mathrm{MIN}}$ recovery and some populations had a larger response to acclimation treatments (plasticity) for cold tolerance than did the South African populations. We also predicted that South African populations would vary more in thermal tolerance traits than the Australian populations, given the longer time frame for evolutionary divergence. We found significant differences in mean responses of populations from South Africa in contrast to the lack of overall difference among the Australia populations. The third prediction was that Australian populations would exhibit similar thermal tolerance responses to the likely source population of $H$. destructor near Cape Town, South Africa. This was not supported, as the Stellenbosch populations differed from Australian populations for HCT and for $\mathrm{CT}_{\text {MIN }}$ recovery.

These results for $H$. destructor are consistent with findings that invasive species can, through range expansion, occupy environments that are not predictable from the native range alone (Broennimann et al., 2007). They also suggest that invasive species can adapt rapidly in the invasive range (e.g. Phillips et al., 

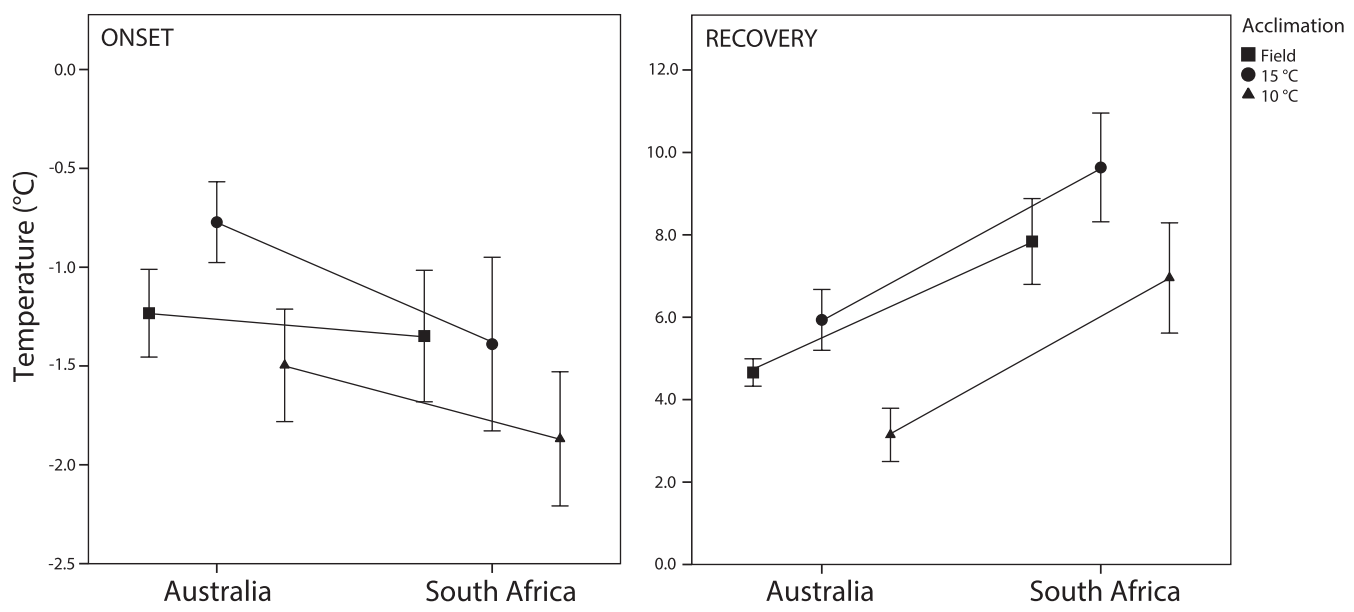

Figure $3 \mathrm{CT}_{\text {MIN }}$ onset and recovery for Australia and South Africa. Points represent means of each treatment within country. Acclimation treatments are shown for field (squares), $15^{\circ} \mathrm{C}$ (circles) and $10{ }^{\circ} \mathrm{C}$ (triangles). Error bars represent one standard error.

Table 3 ANOVAs for critical thermal minimum $\left(\mathrm{CT}_{\mathrm{MIN}}\right)$ onset and recovery of $10^{\circ} \mathrm{C}$ and $15^{\circ} \mathrm{C}$ acclimated populations of Halotydeus destructor between Australia and South Africa. Significant terms $(P<0.05)$ are indicated in bold.

\begin{tabular}{|c|c|c|c|c|c|c|}
\hline Trait/effect & d.f. & $\begin{array}{l}\text { Mean } \\
\text { square }\end{array}$ & $F$ & Error & $\begin{array}{l}\text { d.f. } \\
\text { (error) }\end{array}$ & Significance \\
\hline \multicolumn{7}{|l|}{ Onset } \\
\hline Country & 1 & 3.086 & 2.125 & 1.452 & 5.013 & 0.205 \\
\hline Treat & 1 & 4.676 & 4.846 & 0.965 & 5.017 & 0.079 \\
\hline Pop (country) & 5 & 1.467 & 1.508 & 0.973 & 5 & 0.332 \\
\hline Treat $\times$ country & 1 & 0.19 & 0.197 & 0.964 & 5.019 & 0.675 \\
\hline Pop (treat $\times$ country) & 5 & 0.973 & 6.014 & 0.162 & 39 & $<0.001$ \\
\hline \multicolumn{7}{|l|}{ Recovery } \\
\hline Country & 1 & 181.794 & 10.449 & 17.399 & 5.015 & 0.023 \\
\hline Treat & 1 & 92.193 & 16.116 & 5.721 & 5.041 & 0.010 \\
\hline Pop (country) & 5 & 17.574 & 3.054 & 5.755 & 5 & 0.123 \\
\hline Treat $\times$ country & 1 & 0.001 & 0 & 5.715 & 5.047 & 0.989 \\
\hline Pop (treat $\times$ country) & 5 & 5.755 & 2.459 & 2.340 & 39 & 0.050 \\
\hline
\end{tabular}

pop, population; treat, acclimation treatment.
2006; Urbanski et al., 2012), although further tests are required to determine if evolutionary changes have occurred in $H$. destructor as in these other species. In Australia, H. destructor has expanded into environments with colder minimum temperatures, and the lower recovery trait for $\mathrm{CT}_{\mathrm{MIN}}$ may be reflective of an adaptive shift in cold tolerance. ENMs described different environments for $H$. destructor distributions, and these appear to correlate with observed trait differences, such as cold tolerance. However, the ENMs also suggested that aridity limits the current Australian distribution, but desiccation resistance, which correlates with moisture availability as well as temperature, was not measured here. In an early study, temperatures above $30^{\circ} \mathrm{C}$ played a more dominant role than low humidity in determining survival for $H$. destructor over short time periods (Solomon, 1937). Future experiments could consider the performance of mites across different combinations of thermal and humidity conditions. Temperature and moisture tolerances of other life stages, such as obligate diapause, also define niche limits. Diapause allows $H$. destructor to oversummer and withstand extreme temperatures, although this stage is sensitive to the amount of summer rain (Ridsdill-Smith, 1997; Ridsdill-Smith et al., 2005). Thus adaptive shifts in diapause traits may allow for development in conditions that were not previously viable. Unfortunately, adaptive shift in diapause traits are difficult to measure due to the long development of postdiapause eggs and the interaction of day length, temperature and moisture cues in initiating and breaking diapause (Ridsdill-Smith et al., 2005).

A more complete understanding of the extent and form of adaptation in thermal tolerance traits will require crossgenerational measurements of population/country differences as well as additional studies to assess the heritability of thermal responses (cf. Chown et al., 2009; Mitchell \& Hoffmann, 2010). Because there were no significant interactions between acclimation and country, and because the field temperature covariates used added little to explaining observed differences in thermal responses between countries, we suspect that evolutionary adaptation has occurred in basal traits, reflecting adaptive shifts for 


\begin{tabular}{|c|c|c|c|c|c|c|c|}
\hline & Trait/effect & df & $\begin{array}{l}\text { Mean } \\
\text { square }\end{array}$ & $F$ & Error & $\begin{array}{l}\text { df } \\
\text { (Error) }\end{array}$ & Significance \\
\hline \multicolumn{8}{|l|}{ Onset } \\
\hline \multirow[t]{3}{*}{ Australia } & Treat & 1 & 3.975 & 2.789 & 1.425 & 3.002 & 0.193 \\
\hline & Pop & 3 & 0.458 & 0.321 & 1.428 & 3 & 0.812 \\
\hline & Treat $\times$ pop & 3 & 1.428 & 7.597 & 0.188 & 23 & 0.001 \\
\hline \multirow[t]{3}{*}{ South Africa } & Treat & 1 & 1.241 & 4.290 & 0.289 & 2.004 & 0.174 \\
\hline & Pop & 2 & 2.981 & 10.289 & 0.290 & 2 & 0.089 \\
\hline & Treat $\times$ pop & 2 & 0.290 & 2.336 & 0.124 & 16 & 0.129 \\
\hline \multicolumn{8}{|l|}{ Recovery } \\
\hline \multirow[t]{3}{*}{ Australia } & Treat & 1 & 55.167 & 7.462 & 7.393 & 3.007 & 0.072 \\
\hline & Pop & 3 & 5.762 & 0.778 & 7.404 & 3 & 0.579 \\
\hline & Treat $\times$ pop & 3 & 7.404 & 2.234 & 3.314 & 23 & 0.111 \\
\hline \multicolumn{8}{|l|}{ South Africa } \\
\hline & Treat & 1 & 38.832 & 11.857 & 3.275 & 2.003 & 0.075 \\
\hline & Pop & 2 & 35.291 & 10.757 & 3.281 & 2 & 0.085 \\
\hline & Treat $\times$ pop & 2 & 3.281 & 3.487 & 0.941 & 16 & 0.055 \\
\hline
\end{tabular}

Table 4 ANOVAs for critical thermal minimum $\left(\mathrm{CT}_{\mathrm{MIN}}\right)$ onset and recovery of $10^{\circ} \mathrm{C}$ and $15^{\circ} \mathrm{C}$ acclimated populations of Halotydeus destructor within Australia and South Africa, respectively. Significant terms $(P<0.05)$ are indicated in bold.

pop, population; treat, acclimation treatment.

$H$. destructor, although this requires further testing. The active season of $H$. destructor in Australia coincides with frosty periods, most likely selecting for recovery from low temperature extremes. Cold tolerance traits such as $\mathrm{CT}_{\mathrm{MIN}}$ have been shown to correlate with limits to the distributions of other temperate arthropods (Addo-Bediako et al., 2000; Kellermann et al., 2012). The expansion of $H$. destructor in Australia may reflect such limits. Hotter and drier days also occur more frequently in spring months in Australia towards the end of the active season and this may explain the small increase in HMT for Australian populations. This difference may facilitate population persistence in the area of Australian range expansion, where aridity correlates with distributional limits in contrast to predictions based on South African ENMs.

Acclimation responses were preserved across most populations. Plastic responses like acclimation offset temperature variation and buffer against extreme conditions (Seebacher \& Franklin, 2011), and invasive species can display extended phenotypic plasticity over native counterparts (Slabber et al., 2007), or differences in the form the plasticity takes (Chown et al., 2007). Within this context, it is unclear why the inland Hay population from Australia has lost its acclimation response to cold conditions, and additional populations from this region need to be tested across a wider range of temperatures.

Within Australian populations generally, low variability in thermal tolerances is inconsistent with ENM-generated hypotheses, as populations are found across environments that have different climatic extremes. However, these findings are in accordance with genetic work that points to reduced genetic variation being present in Australia (Weeks et al., 1995; Qin, 1997). Qin (1997) measured allele frequency for five polymorphic loci across South African and Australian populations and found that substructuring in South African populations was high $\left(F_{\mathrm{ST}}\right.$ ranged 0.130 to 0.6435 , mean 0.4340$)$, whereas for Australian populations it was relatively low $\left(F_{\mathrm{ST}}\right.$ ranged from
0.027 to 0.217 , average 0.089 ) (Qin, 1997). The relatively high rates of gene flow across the eastern Australian landscape (Weeks et al., 1995) may also act to reduce any differences among populations, although more markers need to be considered in the genetic analyses.

The thermal tolerance results may provide some insight into how $H$. destructor might respond to climate change. Halotydeus destructor has expanded in Australia and seems to have adapted to colder extremes as well as hotter and drier conditions, which may be advantageous to a species faced with increasing climatic variability. Although $H$. destructor is likely to have currently reached distributional limits in Australia (Hill et al., 2012) it is well buffered against summer temperature extremes (Ridsdill-Smith et al., 2005), and winter eggs of $H$. destructor are adapted to exploit warm winter temperatures (James \& O'Malley, 1991). This makes it likely that this species will continue to be an important pest under the forecasted more variable conditions with milder average winter temperatures.

The use of ENMs for modelling invasive species is often criticized for reasons including non-equilibrium between species and environment (Guisan \& Thuiller, 2005; Gallien et al., 2012). However, by using ENMs to generate hypotheses and select populations for testing thermal tolerance traits, we present a framework to investigate niche conservatism for invasive species. This framework led to the prediction that $H$. destructor has expanded into environments with colder extremes, and led to subsequent experiments on inland populations to test responses to thermal extremes. By now expanding on these ENMs and thermal tolerance traits as well developing breeding designs to separate genetic and non-genetic factors, it should be possible to gain insight into the evolutionary processes underlying $H$. destructor niche shifts and range expansion in Australia. Such studies will also help to predict how adaptive shifts may abet both biological invasions and responses to climate change. 


\section{ACKNOWLEDGEMENTS}

Suzaan Kritzinger-Klopper, Charlene Scheepers and Natalie Theron are thanked for assistance with South African fieldwork. Erika Nortje provided valuable laboratory assistance in South Africa. Elise Furlan and Michael Nash assisted on field collection trips in Australia. M.P.H. is supported by the Grains Research Development Corporation (GRDC) through a Grains Research Scholarship (GRS154) and a National Invertebrate Pest Initiative studentship at the Australian Commonwealth Scientific and Research Organization (CSIRO). Collections in South Africa made under permits 0035-AAA004-00415 and -00416 (CapeNature) and 675/2011 (Nature and Environmental Conservation, Northern Cape Province). A.A.H. is supported by the Australian Research Council.

\section{REFERENCES}

Addo-Bediako, A., Chown, S.L. \& Gaston, K.J. (2000) Thermal tolerance, climatic variability and latitude. Proceedings of the Royal Society B: Biological Sciences, 267, 739-745.

Alford, L., Blackburn, T.M. \& Bale, J.S. (2012) Effects of acclimation and latitude on the activity thresholds of the aphid Myzus persicae in Europe. Journal of Applied Entomology, 136, 332-346.

Broennimann, O., Treier, U.A., Müller-Schärer, H., Thuiller, W., Peterson, A.T. \& Guisan, A. (2007) Evidence of climatic niche shift during biological invasion. Ecology Letters, 10, 701-709.

Buckley, L.B., Urban, M.C., Angilletta, M.J., Crozier, L.G., Rissler, L.J. \& Sears, M.W. (2010) Can mechanism inform species' distribution models? Ecology Letters, 13, 1041-1054.

Chown, S.L., Slabber, S., McGeoch, M.A., Janion, C. \& Leinaas, H.P. (2007) Phenotypic plasticity mediates climate change responses among invasive and indigenous arthropods. Proceedings of the Royal Society B: Biological Sciences, 274, 2531-2537.

Chown, S.L., Jumbam, K.R., Sørensen, J.G. \& Terblanche, J.S. (2009) Phenotypic variance, plasticity and heritability estimates of critical thermal limits depend on methodological context. Functional Ecology, 23, 133-140.

Ebeling, S.K., Hensen, I. \& Auge, H. (2008) The invasive shrub Buddleja davidii performs better in its introduced range. Diversity and Distributions, 14, 225-233.

Ebeling, S.K., Stöcklin, J., Hensen, I. \& Auge, H. (2011) Multiple common garden experiments suggest lack of local adaptation in an invasive ornamental plant. Journal of Plant Ecology, 4, 209-220.

Elith, J. \& Leathwick, J.R. (2009) Species distribution models: ecological explanation and prediction across space and time. Annual Review of Ecology, Evolution, and Systematics, 40, 677977.

Gallien, L., Douzet, R., Pratte, S., Zimmermann, N.E. \& Thuiller, W. (2012) Invasive species distribution models - how violating the equilibrium assumption can create new insights. Global Ecology and Biogeography, 21, 1126-1136.
Gaston, K.J. \& Chown, S.L. (1999) Elevation and climatic tolerance: a test using dung beetles. Oikos, 86, 584-590.

Guisan, A. \& Thuiller, W. (2005) Predicting species distribution: offering more than simple habitat models. Ecology Letters, 8, 993-1009.

Halliday, R. (2005) Predatory mites from crops and pastures in South Africa: potential natural enemies of redlegged earth mite Halotydeus destructor (Acari: Penthaleidae). Zootaxa, 1079, 11-64.

Hazell, S.P., Pedersen, B.P., Worland, M.R., Blackburn, T.M. \& Bale, J.S. (2008) A method for the rapid measurement of thermal tolerance traits in studies of small insects. Physiological Entomology, 33, 389-394.

Hill, M.P., Hoffmann, A.A., Macfadyen, S., Umina, P.A. \& Elith, J. (2012) Understanding niche shifts: using current and historical data to model the invasive redlegged earth mite, Halotydeus destructor. Diversity and Distributions, 18, 191203.

Hoffmann, A.A., Shirriffs, J. \& Scott, M. (2005) Relative importance of plastic vs genetic factors in adaptive differentiation: geographical variation for stress resistance in Drosophila melanogaster from eastern Australia. Functional Ecology, 19, 222-227.

Hoffmann, A.A., Chown, S.L. \& Clusella-Trullas, S. (2012) Upper thermal limits in terrestrial ectotherms: how constrained are they? Functional Ecology. doi: 10.1111/j.13652435.2012.02036.x.

James, D.G. \& O'Malley, K.J. (1991) Effect of temperature on development and survival of eggs of Halotydeus destructor (Tucker) (Acari: Penthaleidae). International Journal of Acarology, 17, 209-212.

Jiménez-Valverde, A., Peterson, A.T., Soberón, J., Overton, J.M., Aragón, P. \& Lobo, J.M. (2011) Use of niche models in invasive species risk assessments. Biological Invasions, 13, 2785-2797.

Kearney, M. \& Porter, W. (2009) Mechanistic niche modelling: combining physiological and spatial data to predict species' ranges. Ecology Letters, 12, 334-350.

Kellermann, V., Loeschcke, V., Hoffmann, A.A., Kristensen, T.N., Fløjgaard, C., David, J.R., Svenning, J.-C. \& Overgaard, J. (2012) Phylogenetic constraints in key functional traits behind species' climate niches: patterns of desiccation and cold resistance across 95 Drosophila species. Evolution, 66, 3377-3389.

Kolbe, J.J., Kearney, M. \& Shine, R. (2010) Modeling the consequences of thermal trait variation for the cane toad invasion of Australia. Ecological Applications, 20, 22732285.

Medley, K.A. (2010) Niche shifts during the global invasion of the Asian tiger mosquito, Aedes albopictus Skuse (Culicidae), revealed by reciprocal distribution models. Global Ecology and Biogeography, 19, 122-133.

Mitchell, K.A. \& Hoffmann, A.A. (2010) Thermal ramping rate influences evolutionary potential and species differences for upper thermal limits in Drosophila. Functional Ecology, 24, 694-700. 
Overgaard, J., Kristensen, T.N. \& Sørensen, J.G. (2011) Validity of thermal ramping assays used to assess thermal tolerance in arthropods. PLoS ONE, 7, e32758.

Petitpierre, B., Kueffer, C., Broennimann, O., Randin, C., Daehler, C. \& Guisan, A. (2012) Climatic niche shifts are rare among terrestrial plant invaders. Science, 335, 13441348.

Phillips, B.L., Brown, G.P., Webb, J.K. \& Shine, R. (2006) Invasion and the evolution of speed in toads. Nature, 439, 803-803.

Qin, T. (1997) Population genetics of redlegged earth mites Halotydeus destructor and H. anthropus (Acarina: Penthaleidae) from Australia and/or South Africa. Bulletin of Entomological Research, 87, 289-298.

Qin, T. \& Halliday, R. (1996) Revision of the Australian and South African species of Halotydeus (Acarina: Penthaleidae). Bulletin of Entomological Research, 86, 441-450.

Ridsdill-Smith, J., Pavri, C., De Boer, E. \& Kriticos, D. (2005) Predictions of summer diapause in the redlegged earth mite, Halotydeus destructor (Acari: Penthaleidae), in Australia. Journal of Insect Physiology, 51, 717-726.

Ridsdill-Smith, T. (1997) Biology and control of Halotydeus destructor (Tucker) (Acarina: Penthaleidae): a review. Experimental and Applied Acarology, 21, 193-223.

Seebacher, F. \& Franklin, C.E. (2011) Physiology of invasion: cane toads are constrained by thermal effects on physiological mechanisms that support locomotor performance. Journal of Experimental Biology, 214, 1437-1444.

Sexton, J.P., McIntyre, P.J., Angert, A.L. \& Rice, K.J. (2009) Evolution and ecology of species range limits. Annual Review of Ecology, Evolution, and Systematics, 40, 415-436.

Sinclair, B.J., Terblanche, J.S., Scott, M.B., Blatch, G.L., Jaco Klok, C. \& Chown, S.L. (2006) Environmental physiology of three species of Collembola at Cape Hallett, North Victoria Land, Antarctica. Journal of Insect Physiology, 52, 29-50.

Slabber, S., Worland, M.R., Leinaas, H.P. \& Chown, S.L. (2007) Acclimation effects on thermal tolerances of springtails from sub-Antarctic Marion Island: indigenous and invasive species. Journal of Insect Physiology, 53, 113-125.

Solomon, M.E. (1937) Experiments on the effects of temperature and humidity on the survival of Halotydeus destructor (Tucker), Acarina fam. Penthaleidae. Australian Journal of Experimental Biology and Medical Science, 15, 1-16.

Strayer, D.L., Eviner, V.T., Jeschke, J.M. \& Pace, M.L. (2006) Understanding the long-term effects of species invasions. Trends in Ecology and Evolution, 21, 645-651.

Terblanche, J.S., Klok, C.J., Krafsur, E.S. \& Chown, S.L. (2006) Phenotypic plasticity and geographic variation in thermal tolerance and water loss of the tsetse Glossina pallidipes (Diptera: Glossinidae): implications for distribution modelling. American Journal of Tropical Medicine and Hygiene, 74, 786-794.
Terblanche, J.S., Deere, J.A., Clusella-Trullas, S., Janion, C. \& Chown, S.L. (2007) Critical thermal limits depend on methodological context. Proceedings of the Royal Society B: Biological Sciences, 274, 2935-2943.

Umina, P.A. \& Hoffmann, A.A. (2005) Competitive interactions among four pest species of earth mites (Acari: Penthaleidae). Journal of Economic Entomology, 98, 307-316.

Umina, P.A., Weeks, A.R., Roberts, J., Jenkins, S., Mangano, G.P., Lord, A. \& Micic, S. (2012) The current status of pesticide resistance in Australian populations of the redlegged earth mite (Halotydeus destructor). Pest Management Science, 68, 889-896.

Urbanski, J., Mogi, M., O’Donnell, D., Decotiis, M., Toma, T. \& Armbruster, P. (2012) Rapid adaptive evolution of photoperiodic response during invasion and range expansion across a climatic gradient. The American Naturalist, 179, 490-500.

Warren, D.L., Glor, R.E. \& Turelli, M. (2010) ENMTools: a toolbox for comparative studies of environmental niche models. Ecography, 33, 607-611.

Weeks, A., Fripp, Y. \& Hoffmann, A. (1995) Genetic structure of Halotydeus destructor and Penthaleus major populations in Victoria (Acari: Penthaleidae). Experimental and Applied Acarology, 19, 633-646.

\section{SUPPORTING INFORMATION}

Additional supporting information may be found in the online version of this article at the publisher's web-site.

Appendix S1 Distribution of Halotydeus destructor in Australia. Appendix S2 Characterizing the environments present across the range expansion of Halotydeus destructor.

\section{BIOSKETCHES}

Matt Hill is a $\mathrm{PhD}$ candidate studying pest invertebrates at the University of Melbourne, Australia. His research combines distribution models, thermal physiology and population genetics to test for niche shifts, and how these are important for species invasion and response to climate change.

Steven Chown is at Monash University and has interests in the mechanistic basis of the responses of organisms to environmental change.

Ary Hoffmann is a professor of ecological genetics and entomology at the University of Melbourne. He has long-standing interests in climate change adaptation and in developing sustainable solutions to pest control issues in broad acre agriculture.

Editor: Joshua Lawlor 